\title{
Determinants of low birth weight in neonates born in three hospitals in Brong Ahafo region, Ghana, 2016- an unmatched case-control study
}

\author{
Zakariah Adam ${ }^{1,2}$, Donne Kofi Ameme ${ }^{1}$, Priscillia Nortey ${ }^{1}$, Edwin Andrew Afari ${ }^{1}$ and Ernest Kenu ${ }^{1 *}$ (D)
}

\begin{abstract}
Background: Each year, about 20 million Low Birth Weight (LBW) babies are born with very high proportion (96.5\%) occuring in developing countries. In the last decade, the incidence of LBW in Ghana has not declined. Brong Ahafo Region of Ghana recorded a LBW prevalence of 11\% which was higher than the the national average of 10\%. This study identifed determinants of LBW delivery in the Brong Ahafo Region.

Methods: We conducted a 1:2 unmatched case control study among mothers with singleton deliveries in 3 major health facilities in the Brong Ahafo Region. A case was defined as a mother who delivered a baby weighing less than $2500 \mathrm{~g}$ in any of the three selected health facilities between 1st December, 2015 and 30th April, 2016. A control was defined as a mother who within $24 \mathrm{~h}$ of delivery by a case, delivered a baby weighing at least $2500 \mathrm{~g}$ and not exceeding $3400 \mathrm{~g}$ in the same health facility. Deliveries that met the inclusion criteria for cases were selected and two controls were randomly selected from the pool of deliveries that meet criteria for controls within $24 \mathrm{~h}$ of delivery of a case. A total of 120 cases and 240 control were recruited for the study. We computed odds ratios at 95\% confidence level to determine the associations between low birth weight and the dependent factors.

Results: After controlling for confounders such as planned pregnancy, mode of delivery, parity and previous LBW in stepwise backward logistic regression, first trimester hemoglobin < $11 \mathrm{~g} / \mathrm{dl}$ (aOR 3.14; 95\%Cl: 1.50-6.58), delivery at 32-36 weeks gestation (aOR 13.70; 95\% Cl: 4.64-40.45), delivery below 32 weeks gestation (aOR 58.5; $95 \% \mathrm{Cl} 6.7-513.9)$, secondary education of mothers (aOR 4.19; $95 \% \mathrm{Cl} 1.45-12.07$ ), living with extended family (aOR 2.43; 95\%Cl 1.15-5.10, living alone during pregnancy (aOR 3.9; 95\%Cl: 1.3-11.7), and not taking iron supplements during pregnancy (aOR 3.2; 95\%Cl: 1.1-9.5) were found to be significantly associated with LBW.

Conclusion: Determinants of LBW were: preterm delivery, mothers with secondary education, living alone during pregnancy, not taking daily required iron supplementation and mothers with first trimester hemoglobin below $11 \mathrm{~g} / \mathrm{dl}$. Education during antenatal sessions should be tailored to address the identified risk factors in the mother and child health care services.
\end{abstract}

Keywords: Low birth weight, Brong Ahafo region, Case control study

\footnotetext{
* Correspondence: ernest_kenu@yahoo.com

${ }^{1}$ Ghana Field Epidemiology and Laboratory Trainning Programme,

Department of Epidemiology and Disease Control, University of Ghana

School of Public Health, Legon, Ghana

Full list of author information is available at the end of the article
}

(c) The Author(s). 2019 Open Access This article is distributed under the terms of the Creative Commons Attribution 4.0 International License (http://creativecommons.org/licenses/by/4.0/) which permits unrestricted use, distribution, and reproduction in any medium, provided you give appropriate credit to the original author(s) and the source, provide a link to the Creative Commons license, and indicate if changes were made. The Creative Commons Public Domain Dedication waiver (http://creativecommons.org/publicdomain/zero/1.0/) applies to the data made available in this article, unless otherwise stated. 


\section{Background}

Low birth weight (LBW) remains a major issue of public health concern globally with a disproportionate burden on low and middle income countries. LBW contributes significantly to morbidity, mortality and disability in neonatal, infancy, and childhood periods. It also has long term effects on health outcomes in adult life.

Low birth weight contributes 60 to $80 \%$ of all neonatal deaths [1]. Therefore, reducing the incident rates of LBW, is essential to reducing child mortality [2]. Progress made in reducing neonatal mortality has been slower in Sub-Saharan Africa compared to any other region in the world [3]. The incidence of LBWs in Ghana for 2014 was 160 per 1000 births. Ghana has not recorded any reduction in LBW in the last decade [4]. In one of the three major tertiary hospitals in Ghana, 16.5\% of the 11,647 babies born were low birth weight in the year 2013 [5]. Also about 46\% of all LBW babies in Ghana die in the first 28 days of life [6]. In the Brong Ahafo region the incidence of LBW was $11.0 \%$ in 2014 , this is higher than the national incidence of $10 \%$. In addition to the LBW of the region being consistently higher than the national average since 2010, it recorded 397 neonatal deaths in 2014 [7]. Together, the hospitals selected for the study recorded 1149 (11.4\%) LBW babies out of the 10,075 live births in the region for 2015 [7]. Care for low birth weight babies comes with substantial costs to the health system and imposes a significant burden on the society as a whole [8]. The weight of a newborn is an important predictor of the infant's growth and survival $[9,10]$. LBW babies from birth are disadvantaged and their survival is very poor. LBW babies have been known to have a higher risk of death compared to infants of normal weight, [11]. A Canadaian study also confirmed that LBW was a significant factor associated with neonatal death [12]. There are risk factors that increase a pregnant woman's chance of having a low birth weight baby. These include: smoking, alcohol consumption, underweight, being younger than 15 years, or older than 35 years. Also the social and economic factors, such as low income, low educational level, stress, domestic violence or other abuse, and being an unmarried woman may increase the risk of a low birth weight delivery. [13-16]. LBW is usually an indicator of chronic maternal malnutrition, maternal illness and poor prenatal care, hence, a good indicator of the socioeconomic status of inhabitants $[17,18]$.

Low birth weight infants are predisposed to both short and long term health problems. Some short term conditions include, respiratory distress syndrome, infections, enterocolitis, hydrocephalus, and mental retardation [19]. Some of the long term conditions are: coronary heart disease, non-insulin dependent diabetes, childhood hypertension, behavioral disorders, impaired cognitive function, and psychological disorders [20-23]. In the Brong Ahafo Region of Ghana, little is known about the factors that predispose the pregnant woman to delivery of a LBW baby. Therefore, identifying these factors will significantly contribute to ongoing efforts to address $\mathrm{LBW}$. A reduction in the incidence of $\mathrm{LBW}$ will reduce the cost of care of the LBW to the healthcare system and eventually reduce neonatal and child mortality.

\section{Methods \\ Study design}

We carried out a 1:2 an unmatched case control study in three major hospitals in Brong Ahafo Region, Ghana from 1st December 2015 to 30th April 2016. These hospitals recorded the largest number of deliveries per year in the region and serve as the major referral centres in the region.

\section{Study site}

The study was conducted in the Brong Ahafo Regional Hospital, Sunyani Municipal Hospital and the Holy Family Hopsital.

Brong Ahafo Regional Hospital is the main referral centre in the region for patients requiring secondary healthcare services. In 2015, data from DHIMS revealed that the hospital recorded a total of 3261 live births with $12.6 \%$ (410/3261) being low birth weight. The hospital has one gynecological theatre, one labour ward, three post-delivery wards and one neonatal unit.

Holy family hospital serves as another referral centre for medical conditions including obstetric and gynecological conditions. It is located in Techiman, which is considered the busiest trading centre of the region. Data from the DHIMS for 2015 showed that the hospital recorded a total of 5152 live births with $12.4 \%$ (641/5152) low birth weight babies. The hospital one labour ward, a post-delivery ward and one neonatal unit.

The Sunyani Municipal Hospital is the third referral hospital and it serves the Sunyani Municipality. It recorded a total of 1662 live births with 5.9\% (98/1662) low birth weights for 2015 (DHIMS 2015). It has one theatre, one labour ward and one post-delivery ward. All the data collected from this hospital were in the records of the post-delivery ward.

\section{Case selection \\ Case}

A case was defined as a mother who delivered a baby weighing less than $2500 \mathrm{~g}$ in any of the three selected health facilities between 1st December, 2015 and 30th April, 2016. 


\section{Control}

A control was defined as a mother who within $24 \mathrm{~h}$ of delivery by a case, delivered a baby weighing at least $2500 \mathrm{~g}$ and not exceeding $3400 \mathrm{~g}$ in the same health facility.

\section{Inclusion criteria}

Mothers with singleton deliveries of babies whose weight is $3400 \mathrm{~g}$ or less. Mothers who consent to participate in the study.

\section{Exclusion criteria}

Babies with congenital abnormalities or still births. Mothers who are critically ill.

\section{Sample size calculation}

A sample size calculation formula for unmatched case control study was used with the following parameters: power of the study was $80 \%, Z_{\beta}=0.84$ and at 0.05 significance level, $Z_{\alpha}=1.96$. The proportion exposed in the control group used was 33\%, thus the exposure was nulliparity in a study carried out in The Gambia (Jammeh et al., 2011).

Minimal detectable odds ratio that was used was 2 . Based on this a total of 360 case control respondent pairs, that is a 1:2 unmatched case control pairs was arrived at. An additional 15\% was added to adjust for missing data.

\section{Data collection technique and tools}

A data collection questionnaire was designed to collect data from mothers who delivered and met the criteria to be included in the study. The questionnaire obtained both primary and secondary data. We obtained the secondary data by reviewing the antenatal and postnatal health records of the mother. The questionnaire was pretested in a health facility with similar characteristics as the study sites. The questionnaire was revised to improve clarity of some of the questions.

The required data from mothers with low birth weight babies were collected within $24 \mathrm{~h}$ upon delivery. Data was collected each time a low birth weight baby was delivered until the required sample size was obtained. The data collection officer visited the post-delivery, labour, and neonatal wards three times each day (morning, afternoon and evening) to identify study participants. Also, the staff on duty at the post delivery, labour, and neonatal units alerted the data collection officer each time a delivery meeting the case definition and inclusion criteria occurred. Data was collected by administering the structured questionnaire to the mother and also recording information from the mothers' antenatal records book and the maternity ward records. Data were collected concurrently in all the three health facilities until the total required sample size was obtained.
Two controls were selected on the same day of delivery of a case by a simple random method. Where more than two controls were delivered within $24 \mathrm{~h}$ after delivery of the case, the controls are assigned numbers which were entered into a random digit selection software to select the controls randomly. This was done concurrently in all the three health until the required sample size was reached.

Consenting mothers were taken to an office within the ward for the questionnaire to be administered to ensure confidentiality.

The data collected included:

Socio demographic information: age, occupation of mother, educational status, income status, baby's sex, marital status, social support status, height, weight, residence, and planning of pregnancy.

Obstetric data included: gestation at booking, gestation at delivery, mode of delivery, family planning methods used, previous abortions, previous delivery of a LBW baby, parity, number of Antenatal Care (ANC) visits.

Medical status information: any chronic medical condition, illness during pregnancy, hospital admissions during pregnancy, intake of required daily dose of iron supplementation, appetite during pregnancy, use of herbal medications during pregnancy and alcohol intake during pregnancy.

Data collection was carried out with the help of two data collection officers. The officers were health professionals trained in the area of maternal and child health. They were selected from the facilities used for the study. They were trained a week prior to commencement of the data collection. They were then introduced to the heads of departments where recruitment was done.

Data was cross-checked for errors and entered using EpiInfo 7 software. Data was saved in password protected files and no one had access to it except for cross-referencing. Filled questionnaires were kept in locked cabinets. Participants were identified by codes.

\section{Data processing and analysis}

Data were analyzed using STATA software Version 13. Continuous variables were summarized into means and proportions, whiles categorical variables were summarized into frequencies.

Bivariate analysis was done between birthweight and each of the independent variables to determine the associations using the chi-square test of proportions. The odds ratios and confidence intervals were reported using 95\% level of significance. All variables in the bivariate analysis with a $p$-value of less than 0.05 was considered for multiple logistic regression analysis. The backward stepwise logistic regression model was used to test for the determinant predictors for LBW. The level of significance for regression analysis was set at $95 \%$. 


\section{Ethical consideration}

We obtained ethical approval from the Ghana Health Service Ethics Review Committee (GHS/ERS 071015). Also, permission was obtained from the Brong Ahafo Regional Health Directorate and the Heads of the Sunyani Regional Hospital, Sunyani Municipal Hospital and Holy Family Hospital to access the participants and their records. The study was explained to participants and their concerns addressed. A written informed consent was obtained from all participants. Each consenting participant signed or thumb printed on the consent form before the questionnaire was administered. For participant who were under 18, consent was sought form their guardians, and the participant provided a written assent to take part in the study. Both the mother or guardian and participant signed a consent form before the interviews were conducted.

\section{Results}

Socio demographic characteristics of study participants A total of 120 cases and 240 controls were studied in the three health facilities. The mean age of the mothers was $28.2 \pm 5.9$ yeras for cases and $29.0 \pm 5.9$ years for controls). About 10.1\% (12/120) of the cases and 11.8\% $(28 / 240)$ of the controls had no formal education. Majority of the mothers; $61.1 \%(73 / 120)$ cases and $73.5 \%$ $(176 / 240)$ of controls lived in urban areas (Table 1$)$.

\section{Anthropometric characteristics of study participants}

Most of the cases, 97.2\%(103/120), and controls, $97.8 \%(221 / 240)$ were at least $1.46 \mathrm{~m}$ tall. Majority of the cases, 56.9\%(58/120), and controls, 63.3\%(138/240) had normal BMI. The associations between the anthropometric measurements and low birth weight (LBW) are summarized in Table 2.

\section{Obstetric characteristics of study participants}

Majority of the mothers had a first trimester ANC attendance $[64.8 \%(68 / 120)$ among cases and $69.1 \%$ $(161 / 240)$ among controls]. Most of them had attended $\mathrm{ANC}$ at least four times during the pregnancy period (82.2\% of cases and $95.8 \%$ of controls). Booking in the 3rd trimester (OR;5.2, 95\%CI:1.70-15.98):, fewer than three ANC visits (OR; 4.94, 95\%CI: 2.12-11.12), unplanned pregnancy (OR:1.6, 95\%CI: 1.00-2.53), delivery by caesarian section (OR:1.64, 95\%CI:1.00-2.68), primiparity (OR: 2.66, 95\% CI: $1.09-6.48$ ), and previous delivery of a LBW/premature baby (OR: 2.6, 95\%CI: 0.95-7.31) were significantly associated with delivery of a LBW baby (Table 3).

\section{Maternal health characteristics of study participants}

The hemoglobin level of $66.6 \%$ (240/360) of the mothers with low birth weight babies was below $11 \mathrm{~g} / \mathrm{dl}$, whiles $47.9 \%(172 / 360)$ of the mothers with normal weight babies had theirs below 11g/dl. First trimester hemoglobin (OR: 2.18, 95\%CI:1.34-3.55), hospital admissions during pregnancy (OR:2.65, 95\%CI: 1.59-4.92), no iron supplementation intake (OR:2.83, 95\%CI:137-5.85) and intake of herbal preparations (OR: 3.02, 95\%CI:1.57-5.84) were significantly associated with delivery of a LBW in the bivariate analysis (Table 4).

\section{Determinants of LBW among study participants}

On multiple logistic regression, first trimester hemoglobin below $11 \mathrm{~g} / \mathrm{dl}$, delivery at $32-36$ weeks gestational age,

Table 1 Socio-demographic characteristics of study participants, Brong Ahafo Region, 2016

\begin{tabular}{|c|c|c|}
\hline Variable & No. of Cases (\%) $(n=120)$ & No. of Control (\%) $(n=240)$ \\
\hline \multicolumn{3}{|l|}{ Age group of mother (years) } \\
\hline 19 and below & $10(8.3)$ & $18(7.5)$ \\
\hline $20-29$ & $51(42.5)$ & $103(42.9)$ \\
\hline $30+$ & $59(49.2)$ & $119(49.6)$ \\
\hline \multicolumn{3}{|l|}{ Marital status of mother } \\
\hline Married & $83(69.2)$ & $186(78.5)$ \\
\hline Not married & $37(30.8)$ & $51(21.5)$ \\
\hline \multicolumn{3}{|l|}{ Mothers occupation } \\
\hline Farming & $17(14.3)$ & $28(11.8)$ \\
\hline Trader/artisan & $63(52.9)$ & $136(57.1)$ \\
\hline Government/formal job & $16(13.4)$ & $33(13.9)$ \\
\hline Unemployed & $23(19.3)$ & $41(17.2)$ \\
\hline \multicolumn{3}{|l|}{ Residence of mother } \\
\hline Urban & $69(61.1)$ & $172(73.5)$ \\
\hline Rural & 44 (38.9) & $62(26.5)$ \\
\hline
\end{tabular}


Table 2 Bivariate analysis of anthropometric characteristics of study participants, Brong Ahafo Region, 2016

\begin{tabular}{|c|c|c|c|c|c|}
\hline Variables & $\begin{array}{l}\text { Cases }(N=120) \\
N(\%)\end{array}$ & $\begin{array}{l}\text { Controls }(N=240) \\
N(\%)\end{array}$ & OR & $95 \% \mathrm{Cl}$ & $p$-value \\
\hline \multicolumn{6}{|l|}{ Mothers height(m) } \\
\hline $1.46 \mathrm{~m}$ or above (normal) & $103(97.2)$ & $221(97.8)$ & 1 & & ref \\
\hline Below 1.46 m(short) & $3(2.8)$ & $5(2.2)$ & 1.29 & $0.20-6.75$ & $0.50^{\wedge}$ \\
\hline \multicolumn{6}{|l|}{ Mothers weight } \\
\hline $45 \mathrm{~kg}$ and above & $107(97.3)$ & $219(96.5)$ & 1 & & ref \\
\hline Below 45 kg & $3(2.7)$ & $8(3.5)$ & 0.77 & $0.13-3.27$ & $0.50^{\wedge}$ \\
\hline \multicolumn{6}{|l|}{ BMI of mother $\left(\mathrm{kg} / \mathrm{m}^{2}\right)$} \\
\hline 18.5-24.9 (normal) & $58(56.9)$ & $138(63.3)$ & 1 & & ref \\
\hline Below 18.5 (underweight) & $3(2.9)$ & $13(6.0)$ & 0.55 & $0.15-2.01$ & 0.36 \\
\hline Above 24.9(obese) & $41(40.2)$ & $67(30.7)$ & 1.46 & $0.89-2.40$ & 0.14 \\
\hline
\end{tabular}

${ }^{\wedge}$-fischer exact $p$-value

Table 3 Obstetric characteristics of study participants, Brong Ahafo Region, 2016

\begin{tabular}{|c|c|c|c|c|c|}
\hline Variables & $\begin{array}{l}\text { Cases }(N=120) \\
N(\%)\end{array}$ & $\begin{array}{l}\text { Controls }(N=240) \\
N(\%)\end{array}$ & OR & $95 \% \mathrm{Cl}$ & $P$-value \\
\hline \multicolumn{6}{|l|}{ Gestation at booking } \\
\hline 1st trimester & $68(64.8)$ & $161(69.1)$ & 1 & & ref \\
\hline 2nd trimester & $26(24.8)$ & $67(28.8)$ & 0.92 & $0.54-1.57$ & 0.76 \\
\hline 3rd trimester & $11(10.5)$ & $5(2.1)$ & 5.21 & $1.70-15.98$ & $<0.001$ \\
\hline \multicolumn{6}{|l|}{ ANC visits } \\
\hline 4 and above & $97(82.2)$ & $228(95.8)$ & 1 & & Ref \\
\hline $0-3$ & $21(17.8)$ & $10(4.2)$ & 4.94 & $2.12-11.12$ & $<0.001$ \\
\hline \multicolumn{6}{|l|}{ Planned pregnancy } \\
\hline Yes & $64(53.8)$ & $155(65.1)$ & 1 & & ref \\
\hline No & $55(46.2)$ & $83(34.9)$ & 1.6 & $1.00-2.53$ & 0.038 \\
\hline \multicolumn{6}{|l|}{ Mode of delivery } \\
\hline Spontaneous & $73(61.3)$ & $172(72.3)$ & 1 & & Ref \\
\hline Caesarian section & $46(38.7)$ & $66(27.7)$ & 1.64 & $1.00-2.68$ & 0.036 \\
\hline \multicolumn{6}{|l|}{ Parity } \\
\hline Nulliparity & $44(37.3)$ & $62(26.1)$ & 2.66 & $1.09-6.48$ & 0.024 \\
\hline Primiparity & $21(17.80$ & $55(23.1)$ & 1.43 & $0.56-3.65$ & 0.45 \\
\hline Multiparty(2-3) & $45(38.1)$ & $91(38.2)$ & 1.85 & $0.78-4.41$ & 0.16 \\
\hline Grand multiparity(4+) & $8(6.8)$ & $30(12.6)$ & 1 & & ref \\
\hline \multicolumn{6}{|l|}{ Family planning method } \\
\hline No & $84(70.0)$ & $185(77.1)$ & 1 & & Ref \\
\hline Yes & $36(30.0)$ & $55(22.9)$ & 1.45 & $0.86-2.44$ & 0.14 \\
\hline \multicolumn{6}{|l|}{ Previous abortion } \\
\hline No & $96(80.0)$ & $192(80.0)$ & 1 & & ref \\
\hline Yes & $24(20.0)$ & $48(20.0)$ & 1.01 & $0.55-1.79$ & 0.99 \\
\hline \multicolumn{6}{|c|}{ Previous LBW/premature Delivery } \\
\hline No & 109 (90.8) & $232(96.3)$ & 1 & & ref \\
\hline Yes & $11(9.2)$ & $9(3.7)$ & 2.6 & $0.95-7.31$ & 0.034 \\
\hline
\end{tabular}


Table 4 Bivariate analysis of the maternal health characteristics of study participants, Brong Ahafo Region, 2016

\begin{tabular}{|c|c|c|c|c|c|}
\hline Variables & $\begin{array}{l}\text { Cases }(N=120) \\
N(\%)\end{array}$ & $\begin{array}{l}\text { Controls }(N=240) \\
N(\%)\end{array}$ & OR & $95 \% \mathrm{Cl}$ & $p$-value \\
\hline \multicolumn{6}{|c|}{ First trimester hemoglobin } \\
\hline $11 \mathrm{~g} / \mathrm{dl}$ and above & $39(33.3)$ & $124(52.1)$ & 1 & ref & \\
\hline Below $11 \mathrm{~g} / \mathrm{dl}$ & $78(66.6)$ & $114(47.9)$ & 2.18 & $1.34-3.55$ & $<0.001$ \\
\hline \multicolumn{6}{|c|}{ Hospital admissions in pregnancy } \\
\hline No & $72(60.0)$ & $191(79.9)$ & 1 & ref & \\
\hline Yes & $48(40)$ & $48(20.1)$ & 2.65 & $1.59-4.42$ & $<0.001$ \\
\hline \multicolumn{6}{|c|}{ Iron supplementation intake } \\
\hline Always & $69(57.5)$ & $175(73.2)$ & 1 & ref & \\
\hline Not regularly & $32(26.7)$ & $47(19.7)$ & 1.73 & $1.01-2.94$ & 0.042 \\
\hline Never & $19(15.8)$ & $17(7.1)$ & 2.83 & $1.37-5.85$ & $<0.001$ \\
\hline \multicolumn{6}{|l|}{ Poor appetite } \\
\hline No & $49(41.2)$ & $122(52.6)$ & 1 & ref & \\
\hline Yes & $70(58.8)$ & $110(47.4)$ & 1.58 & $0.99-2.54$ & 0.043 \\
\hline \multicolumn{6}{|l|}{ Poor appetite } \\
\hline No & $49(41.2)$ & $122(52.6)$ & 1 & & ref \\
\hline Yes & $70(58.8)$ & $110(47.4)$ & 1.58 & $0.99-2.54$ & 0.043 \\
\hline \multicolumn{6}{|c|}{ Intake of Herbal medications } \\
\hline No & $92(76.7)$ & $218(90.8)$ & 1 & & ref \\
\hline Yes & $28(23.3)$ & $22(9.2)$ & 3.02 & $1.57-5.84$ & $<0.001$ \\
\hline
\end{tabular}

delivery before 32 weeks gestational age, and secondary education of mother were significantly associated with LBW (Table 5).

\section{Discussion}

The study was conducted to identify determinants of LBW delivery in the three selected health facilities in the Brong Ahafo region of Ghana.

Women younger than 19 years had an increased odds of delivering a low birth weight baby. This is because, adolescent mothers may not have a fully developed reproductive system. A study by Guimares and colleagues has shown that adolescent $(<20$ years of age) mothers have poorer socioeconomic and reproductive conditions as compared with older age groups and this increases the risk of having a LBW baby [24]. With respect to educational level, mothers with secondary education had a four-fold increased odds of delivering a LBW baby compared to mothers with tertiary education. In keeping with findings from our study, a meta-analysis by Silverstrin and his team showed that having a higher education had a protective effect, whereas having a medium education had no protective effects [25] .

Social support which is a measure of support from family, the baby's father, and general functional support is a necessary factor for good pregnancy outcomes [26]. Lack of social support has been associated with increased risk of LBW [27]. In our study the social support system referred to who the mother lived with during the pregnancy. The study shows a four fold increased odds of having a LBW delivery for a mother who lived alone, compared with one who lived with a partner or the unborn baby's father during the pregnancy. A study by Feldman showed that social support was linked with infant birth weight through processes of fetal growth [26]. This suggests that, poor social support during pregnancy could affect fetal growth and result in a low birth weight.

Majority of the participants had their anthropometric measurements within the normal ranges. A short, overweight, or obese woman had an increased odds of having a LBW baby. However, these asssocaitions were not statistically significant, and this is not surprising because one meta-analysis concluded that anthropometric measurements are not good predictors of LBW [28].

Iron deficiency has been reported as the commonest cause of anemia in pregnancy [29]. Anaemia in pregnancy is associated with an increased odds of having LBW babies [30], and our study findings supports association. A meta-analysis by Imdad has shown that iron supplementation significantly reduces the incidence of anemia in pregnancy by about $20 \%$. Our study also revealed that mothers who never took daily required iron supplementation during pregnancy had a threefold increased odds of delivering a LBW baby [29]. 
Table 5 Determinants of Low Birth Weight among study participants, Brong Ahafo Region, 2016

\begin{tabular}{|c|c|c|c|c|}
\hline Characteristics & $\begin{array}{l}\text { Cases } \\
N=120(\%)\end{array}$ & $\begin{array}{l}\text { Controls } \\
N=240 \text { (\%) }\end{array}$ & $\begin{array}{l}\text { cOR } \\
(95 \% \mathrm{Cl})\end{array}$ & $\begin{array}{l}\text { aOR } \\
(95 \% \mathrm{C})\end{array}$ \\
\hline \multicolumn{5}{|l|}{ Gestation at delivery } \\
\hline Term delivery(37-40 weeks) & $76(63.3)$ & $228(95.8)$ & 1 & 1 \\
\hline Preterm delivery(32-36 weeks) & $32(26.4)$ & $9(3.8)$ & $10.5^{*}(4.46-24.68)$ & $13.70^{*}(4.64-40.45)$ \\
\hline Severe preterm delivery ( $<32$ weeks) & $12(10.3)$ & $1(0.4)$ & $61.89 *(6.84-560.33)$ & $58.50^{*}(6.66-513.87)$ \\
\hline \multicolumn{5}{|l|}{ Educational level of mother } \\
\hline Post-secondary/tertiary & $16(13.4)$ & $43(18.1)$ & 1 & 1 \\
\hline Primary/JHS & $35(29.4)$ & $101(42.0)$ & $0.94(0.47-1.88)$ & $1.15(0.39-3.40)$ \\
\hline Secondary & $57(47.1)$ & $68(28.2)$ & $2.25^{*}(1.13-4.47)$ & $4.19^{*}(1.45-12.07)$ \\
\hline No formal education & $12(10.1)$ & $28(11.8)$ & $1.16(0.47-2.81)$ & $1.88(0.46-7.63)$ \\
\hline \multicolumn{5}{|l|}{ Supplementary iron intake } \\
\hline Regular intake & $69(57.5)$ & $175(73.2)$ & 1 & 1 \\
\hline Irregular intake & $32(26.7)$ & $47(19.7)$ & $1.73^{*}(1.01-2.94)$ & $2.19(0.99-4.84)$ \\
\hline No intake & $19(15.8)$ & $17(7.1)$ & $2.83^{*}(1.37-5.85)$ & $3.19 *(0.99-4.84)$ \\
\hline \multicolumn{5}{|l|}{ Who mother lived with during pregnancy } \\
\hline Partner & $55(46.2)$ & $157(65.4)$ & 1 & 1 \\
\hline Extended family & $41(34.5)$ & $63(26.2)$ & $1.86^{*}(1.12-3.09)$ & $2.43^{*}(1.15-5.10)$ \\
\hline Lived alone & $23(19.3)$ & $20(8.4)$ & $3.24^{*}(1.62-6.48)$ & $3.95^{*}(1.33-11.74)$ \\
\hline \multicolumn{5}{|l|}{ 1st trimester hemoglobin } \\
\hline $11 \mathrm{~g} / \mathrm{dl}$ and above & 39 (33.3) & $125(52.1)$ & 1 & 1 \\
\hline Below $11 \mathrm{~g} / \mathrm{dl}$ & $78(66.6)$ & $115(47.9)$ & $2.18^{*}(1.34-3.55)$ & $3.14^{*}(1.50-6.58)$ \\
\hline \multicolumn{5}{|l|}{ Hospital admissions during pregnancy } \\
\hline No & $72(60.0)$ & $192(79.9)$ & 1 & 1 \\
\hline Yes & $48(40)$ & $48(20.1)$ & $2.65^{*}(1.59-4.42)$ & $2.08(1.00-4.30)$ \\
\hline
\end{tabular}

${ }^{*} p$-value for the odds ratio is less than 0.05

OR Odds Ratio, aOR Adjusted Odds Ratio, CI Confidence Interval

Our study had a few limitations. We obtained mothers' hemoglobin levels from their antenatal records and used it to assess anemia as a risk factor to LBW. Since mothers attend ANC clinic at different gestational ages. It would have been more accurate to follow the trends of their hemoglobin levels from the beginning of their antenatal period to delivery in assessing the association of anemia to LBW. Data on weight gain and height obtained from mothers' antenatal record cards were the weights and heights of mothers at initiation of ANC, and therefore, associations between weight gain during pregnancy and actual BMI of the mother during pregnancy. These limitations notwithstanding, the study has revealed some important risk factors that may contribute to the occurrence of low birth weight in the Brong Ahafo Region.

\section{Conclusion}

Preterm delivery, mothers with secondary education, living alone during pregnancy, not taking daily required iron supplementation and mothers with first trimester hemoglobin below $11 \mathrm{~g} / \mathrm{dl}$ are determinants of LBW.
Maternal anthropometric measurements do not influence birth weight. We recommend that the regional and the municipal health directorates in the Brong Ahafo region intensify education of all pregnant women on the need to take iron supplementation during pregnancy to prevent anemia and consequent LBW. Establishment of preconception clinics by the Ministry of Health to identify high risk pregnancies in all health facilities will add to the efforts at preventing negative birth outcomes.

\section{Abbreviations}

ANC: Antenatal Care; BMI: Body Mass Index; CS: Caesarian section; DHIMS: District Health Information Management System; ELBW: Extremely Low Birth Weight; GDHS: Ghana Demographic and Health Survey; GSS: Ghana Statistical Service; ICD: International Classification of Disease; IUGR: Intrauterine Growth Restriction; LBW: Low birth weight; LMIC: Low and Middle Income Countries; MDG: Millennium Development Goals; PTB: Preterm birth; SGA: Small for Gestational Age; SVD: Spontaneous Vaginal Delivery; VLBW: Very Low Birth Weight; WHO: World Health Organization

\section{Acknowledgments}

I acknowledge the roles played by the entire staff of the Department of Epidemiology and Disease Control, School of Public Health.

I would like to also thank the Ghana Field Epidemiology and Laboratory Training Programme secretariat for the assistance in making this work a reality. 
Special thanks go to the Regional Health Directorate, Brong Ahafo Region, The Regional Hospital, Sunyani, The Sunyani Municipal Hospital and The Holy Family Hospital, Techiman for the diverse contributions and assistance they gave to ensure the success of this work.

My thanks also goes to the study participants who gave their time and information to make this study possible.

Finally I would like to acknowledge Mr. Faisal Keliou for his immense support during this work.

\section{Funding}

This work was funded by West Africa Health Organization through Ghana field epidermioogy and laboratory training programme.

\section{Availability of data and materials}

All data generated or analysed during this study are included in this published article [and its supplementary information files].

\section{Authors' contributions}

ZA conceptualization of idea, collected data, did the analysis, drafted the manuscript and assisted in finalizing manuscript. PN-conceptualization of idea, drafed the manuscript and assisted in finalizing it. DKA assisted in data analysis, drafting of manuscript and finalizing the manuscript. EK conceptualization of idea, drafted the manuscript and assisted in finalizing of the manuscript. EAA- conceptualization of idea, drafted the manuscript and assisted in finalizing of the manuscript. All authors read and approved the final version of the manuscript.

\section{Ethics approval and consent to participate}

The study proposal had ethical approval from the Ethical Review Board of the Ghana Health Service. Permission was also obtained from the Brong Ahafo Regional Health Directorate to access the selected facilities. Permission was also obtained from the Heads of the selected institutions. The study was explained to participants and their concerns addressed. A written consent was sought from all participants. An informed consent document was administered to all the participants before they took part in the study. Each participant who agreed to be part of the study signed or thumb printed on the consent form before the questionnaire was administered. For participants who were under 18, a written consent was sought form their guardian and the participant provided a written assent to take part in the study. Both the mother or guardian and the participant signed a consent form before the interviews were conducted.

\section{Consent for publication}

Not applicable.

\section{Competing interests}

The authors declare that they have no competing interests.

\section{Publisher's Note}

Springer Nature remains neutral with regard to jurisdictional claims in published maps and institutional affiliations.

\section{Author details}

'Ghana Field Epidemiology and Laboratory Trainning Programme, Department of Epidemiology and Disease Control, University of Ghana School of Public Health, Legon, Ghana. ${ }^{2}$ Ghana Health Service, Bolgatanga Regional Health Directorate, Bolgatanga, Ghana.

\section{Received: 1 August 2017 Accepted: 25 April 2019}

Published online: 16 May 2019

\section{References}

1. United nations Children's fund and World Health Organization. Low birthweight: Country, regional and global estimates. New York: UNICEF; 2004. http://apps.who.int/iris/bitstream/handle/10665/43184/9280638327. pdf;jsessionid=516BBF714932E8FCDD851972E43215FA? sequence $=1$

2. Lawn JE, Cousens S, Zupan J. 4 million neonatal deaths: when? Where? Why? Lancet. 2005:365(9462):891-900. https://doi.org/10.1016/S01406736(05)71048-5.
3. AbouZahr C, Wardlaw T. Maternal mortality at the end of a decade: signs of progress? Bull World Health Organ. 2001;79(6):561-73. https://doi.org/10. 1590/S0042-96862001000600013.

4. Ghana Statistical Service (GSS), Ghana Health Service (GHS), and ICF International. Ghana Demographic and Health Survey 2014. Rockville: GSS, GHS, and ICF International; 2015. Accessed 12 Dec 2015

5. Korle Bu Teaching Hospital. 2013 Annual Report. Accra: Korle Bu Teaching; 2013. Retrieved from: http://kbth.gov.gh/assets/downloads/pdf/KorlebuAnnual-Report-2013.pdf. Accessed 20 May 2018

6. Ghana Statistical Service (GSS). Ghana multiple Indicator cluster survey with an enhanced malaria module and biomarker, final report. Accra: GSS; 2011. http://dhsprogram.com/pubs/pdf/FR262/FR262.pdf

7. Ghana Health Service. District Health Inforamtion Management Systems 2. 2015. https://www.chimgh.org/dhims/dhis-web-commons/. Accessed 20 Apr 2016.

8. World Health Organization. Regional consultation towards the development of a strategy for optimizing fetal growth and development. Cairo: World Health Organization; 2005

9. Ashworth A. Effects of intrauterine growth retardation on mortality and morbidity in infants and young children. Eur J Clin Nutr. 1998;52(Suppl 1): S34-41 discussion S41-S42.

10. McIntire DD, Bloom SL, Casey BM, Leveno KJ. Birth weight in relation to morbidity and mortality among newborn infants. N Engl J Med. 1999; 340(16):1234-8. https://doi.org/10.1056/NEJM199904223401603.

11. Kinney MV, Kerber KJ, Black RE, Cohen B, Nkrumah F, Coovadia H, et al. SubSaharan Africa's mothers, newborns, and children: where and why do they die. PLoS Med. 2010;7(6):e1000294.

12. Bernstein IM, Horbar JD, Badger GJ, Ohlsson A, Golan A. Morbidity and mortality among very-low-birth-weight neonates with intrauterine growth restriction. Am J Obstet Gyecol. 2000;182(1 Pt 1):198-206.

13. Demelash H, Motbainor A, Nigatu D, Gashaw K, Melese A. Risk factors for low birth weight in bale zone hospitals, south-East Ethiopia : a case-control study. BMC Pregnancy Childbirth. 2015;15:264. https://doi.org/10.1186/ s12884-015-0677-y.

14. Kayode GA, Amoakoh-Coleman M, Agyepong IA, Ansah E, Grobbee DE, Klipstein-Grobusch K. Contextual risk factors for low birth weight: a multilevel analysis. PLoS One. 2014;9(10):e109333.

15. Bhaskar RK, Deo KK, Neupane U, Chaudhary Bhaskar S, Yadav BK, Pokhare HP, Pokharel PK. A case control study on risk factors associated with low birth weight babies in eastern Nepal. Int J Pediatr. 2015;2015:1-7. https:// doi.org/10.1155/2015/807373

16. Baghianimoghadam MH, Baghianimoghadam B, Ardian N, Alizadeh E. Risk factors of low birth weight and effect of them on growth pattern of children up to sixth months of life: a cross-sectional study. J Educ Health Promot. 2015;4:40. https://doi.org/10.4103/2277-9531.157226.

17. UNICEF, WHO. Low birthweight: country, regional and global estimates. New York: UNICEF, Editorial and publications section; 2004. p. 1-27.

18. Agrawal V, Agrawal P, Chaudhary V, Agarwal K, Agarwal A. Prevalence and determinants of "low birth weight" among institutional deliveries. Ann Niger Med. 2011;5(2):48. https://doi.org/10.4103/0331-3131.92950

19. Lira PIC, Ashworth A, Morris SS. Low birth weight and morbidity from diarrhea and respiratory infection in Northeast Brazil. J Pediatr. 1996;128(4): 497-504. https://doi.org/10.1016/S0022-3476(96)70360-8.

20. Eriksson JG Tuomilehto J, Winter PD, Osmomnd C, Barker DJP. FT. Carch-up growth in childhood and death from coronary disease: longitudinal study. BMJ. 1999:318:427-31

21. Leon DA, Lithell HO, Vâgerö D, Koupilová I, Mohsen R, Berglund L, et al. Reduced fetal growth rate and increased risk of death from ischaemic heart disease: cohort study of 15000 Swedish men and women born 1915-29. BMJ (Clinical Research Ed). 1998:317(7153):241-5.

22. Leger J, Levy-Marchal C, Bloch J, Pinet A, Chevenne D, Porquet D, et al. Reduced final height and indications for insulin resistance in 20 year olds born small for gestational age: regional cohort study. BMJ (Clinical Research Ed). 1997:315(7104):341-7. https://doi.org/10.1136/bmj.315.7104.341.

23. Forrester TE, Wilks RJ, Bennett Fl, Simeon D, Osmond C, Allen M, et al. Fetal growth and cardiovascular risk factors in Jamaican schoolchildren. BMJ (Clinical Research Ed.). 1996;312(7024):156-60. https://doi.org/10.1136/bmj. 312.7024.156.

24. Guimarães AM, d'Avila N, Bettiol H, Souza L, De Gurgel RQ, Almeida MLD, et al. Is adolescent pregnancy a risk factor for low birth weight? Rev Saude Publica. 2013;47(1):11-9. https://doi.org/10.1590/S0034-89102013000100003. 
25. Silvestrin S, Silva CH, Da Hirakata VN, Goldani AS, Silveira PP, Goldani MZ. Maternal education level and low birth weight: a meta-analysis. J Pediatr. 2013;89(4):339-45. https://doi.org/10.1016/j.jped.2013.01.003.

26. Feldman PJ, Dunkel-Schetter C, Ca S, Wadhwa PD. Maternal social support predicts birth weight and fetal growth in human pregnancy. Psychosom Med. 2000;62(5):715-25. https://doi.org/10.1097/00006842-200009000-00016.

27. Wado YD, Afework MF, Hindin MJ. Effects of maternal pregnancy intention, depressive symptoms and social support on risk of low birth weight: a prospective study from southwestern Ethiopia. PLoS One. 2014;9(5):e96304. https://doi.org/10.1371/journal.pone.0096304.

28. Goto E. Maternal anthropometric measurements as predictors of low birth weight in developing and developed countries. Arch Gynecol Obstet. 2015; 292(4):829-42. https://doi.org/10.1007/s00404-015-3721-2.

29. Imdad A, Za B. Routine iron/folate supplementation during pregnancy: effect on maternal anaemia and birth outcomes. Paediatr Perinat Epidemiol. 2012;26(SUPPL. 1):168-77. https://doi.org/10.1111/j.1365-3016.2012.01312.x.

30. Sharma SR, Giri S, Timalsina U, Bhandari SS, Basyal B, Wagle K, Shrestha L. Low birth weight at term and its determinants in a tertiary hospital of Nepal : a case control study. PubMed Commons Peer-Reviewed Open Access Scientific Journal. 2015;10(4):4-5. https://doi.org/10.1371/journal. pone.0123962

Ready to submit your research? Choose BMC and benefit from:

- fast, convenient online submission

- thorough peer review by experienced researchers in your field

- rapid publication on acceptance

- support for research data, including large and complex data types

- gold Open Access which fosters wider collaboration and increased citations

- maximum visibility for your research: over $100 \mathrm{M}$ website views per year

At BMC, research is always in progress.

Learn more biomedcentral.com/submissions 